\title{
DETERMINACIÓN DE ANTICUERPOS CONTRA Toxoplasma gondii EN BÚFALOS DE AGUA (Bubalus bubalis) EN EL DISTRITO DE JENARO HERRERA, LORETO, PERÚ
}

\author{
Determination of ANTIBOdies against Toxoplasma gondi IN BUfFalos \\ (Bubalus bubalis) of Jenaro Herrera District, Loreto, Peru
}

Karla Esteves V. ${ }^{1}$, Amanda Chávez V. ${ }^{1,3}$, Eva Casas A. ${ }^{1}$, Olga Lí E. ${ }^{2}$

\section{Resumen}

\begin{abstract}
El objetivo del estudio fue determinar la seroprevalencia de Toxoplasma gondii en búfalos del distrito de Jenaro Herrera, región Loreto, Perú. Se recolectaron 70 muestras de sangre de búfalos hembras en agosto de 2008 para la detección de anticuerpos contra $T$. gondii mediante las técnicas diagnósticas de hemaglutinación indirecta (HAI) e inmunofluorescencia indirecta (IFI). Los resultados indicaron que el $35.7 \pm 11.2 \%$ de las muestras fueron positivas a HAI y el $17.1 \pm 8.8 \%$ a IFI.
\end{abstract}

Palabras clave: toxoplasmosis, búfalos, HAI, IFI, seroprevalencia

\section{Abstract}

The aim of this study was to determine the seroprevalence of Toxoplasma gondii in buffalos in the Jenaro Herrera district, Loreto, Peru. A total of 70 blood samples were collected in female buffalos for the detection of antibodies against $T$. gondii by the Indirect Hemaglutination Test (IHA) and the Indirect Immunofluorescence Test (IFI). The results showed that $35.7 \pm 11.2 \%$ of the samples were positive by IHA and $17.1 \pm$ $8.8 \%$ were positive by IFI.

Key words: toxoplasmosis, buffalo, IHA, IFI, seroprevalence

\footnotetext{
${ }^{1}$ Laboratorio de Microbiología y Parasitología Veterinaria, ${ }^{2}$ Laboratorio de Patología Clínica y Biología Molecular, Facultad de Medicina Veterinaria, Universidad Nacional Mayor de San Marcos, Lima

${ }^{3}$ E-mail: achavezvg@gmail.com
}

Recibido: 24 de julio de 2012

Aceptado para publicación: 11 de abril de 2013 


\section{INTRODUCCIÓN}

La toxoplasmosis es una enfermedad parasitaria de distribución mundial producida por el Toxoplasma gondii, protozoario cuyos hospederos definitivos son los miembros de la familia Felidae y los hospederos intermediarios son las aves y mamíferos, incluido el hombre. Este parásito ocasiona problemas reproductivos en la ganadería, que se traducen en infertilidad, aborto, muerte fetal, momificación y mortalidad neonatal, presentándose como incidentes esporádicos pero que pueden llegar a afectar a una proporción importante de las hembras gestantes (Rojas et al., 1989).

En el Perú se ha reportado la seroprevalencia de $T$. gondii en varias especies domésticas. Se encontró el $17 \%$ en bovinos utilizando la prueba de inmunofluorescencia - IFI (Tejada y Balbin, 1989). En otras especies, utilizando mayormente la prueba de hemaglutinación indirecta (HAI), se reportan una diversidad de valores; por ejemplo, de 10 a 32\% en llamas (Gómez et al., 2003; Saravia et al., 2004), 21 a 53\% en alpacas (Gómez et al., 2003; Poma et al., 2008), $14.9 \%$ en vicuñas (Pastor et al., 2003), 39 a $85 \%$ en ovinos (Rojas, 1990; Caldas, 2005), 57.9\% en caprinos (Vidal, 1990) y de $27.7 \%$ en cerdos (Saavedra y Ortega, 2004). Se requiere identificar las causas de la gran variación de la seroprevalencia a toxoplasmosis en las especies animales de producción, así como en las áreas geográficas del país, a fin de determinar las zonas de mayor riesgo para la salud pública.

La crianza de búfalos de agua (Bubalus bubalis) en el continente americano está cada vez más difundida, pudiendo encontrarse en Argentina, Bolivia, Brasil, Colombia, Cuba, Ecuador, Paraguay, Perú, Venezuela y Trinidad y Tobago, entre otros países (Borghese y Mazzi, 2005). Estudios de seroprevalencia de toxoplasma en búfalos de agua en India reportan valores de $100 \%$ (Selvaraj et al., 2007) y en Irán, usando la técnica modifica- da de aglutinación (MAT), se reportan valores de 7 y $4 \%$ con diluciones de 1:25 y 1:50, respectivamente (Hamidinejat et al., 2010), en tanto que en Brasil se han encontrado prevalencias de 3.8 a 49.9\% (Gondim et al., 1999; Melo de Souza, 2001).

La población de búfalos de agua en el Perú se estima en 30000 cabezas (Almaguer, 2007). Esta especie fue introducida en la llanura amazónica peruana en 1966 por la Universidad Nacional de la Amazonía Peruana (Isuiza et al., 1996), tornándose como una especie productiva de importancia para la economía rural. El distrito de Jenaro Herrera, ubicado en el noreste de la selva peruana, provincia de Requena, Loreto, cuenta con 402 cabezas dedicadas a la producción lechera (García, 2006). Los criadores de búfalos conforman un $99 \%$ de la población del distrito, prevaleciendo el sistema de crianza extensivo, y donde solo el $44 \%$ de los criadores estabula el ganado por las noches. Los ganaderos poseen, además, equinos, vacunos, porcinos y caprinos (García, 2006).

Existe escasa información sobre las enfermedades parasitarias que pueden afectar a los búfalos de agua de la llanura amazónica, por lo que el objetivo del presente estudio fue determinar la seroprevalencia de $T$. gondii en esta especie.

\section{Materiales y Métodos}

El estudio se desarrolló en agosto de 2008 en el distrito Jenaro Herrera, ubicado en la margen derecha del bajo Ucayali, Perú. La zona es considerada como bosque húmedo tropical, con una precipitación promedio anual de $2759 \mathrm{~mm}$, temperatura media de $26.8{ }^{\circ} \mathrm{C}$ con máxima de 32.6 y mínima de $21.1^{\circ} \mathrm{C}$, y humedad relativa promedio anual de $87 \%$ (Isuiza et al., 1996), y se encuentra a una altitud de $125 \mathrm{msnm}$.

El tamaño muestral se calculó mediante el método para una proporción de una población conocida (Thrusfield, 1990), consi- 
Cuadro 1. Seroprevalencia (promedio \pm d.e.) de Toxoplasma gondii en búfalos de agua hembras en edad productiva, del distrito de Jenaro Herrera, Loreto, Perú (2008)

\begin{tabular}{cccc}
\hline \multirow{2}{*}{ Edad (años) } & \multirow{2}{*}{$\begin{array}{c}\text { Animales } \\
\text { muestreados }\end{array}$} & \multicolumn{2}{c}{ Seroprevalencia (\%) } \\
\cline { 3 - 4 } & 16 & $12.5 \pm 7.7$ & $\mathrm{HAI}^{1}$ \\
\hline $2-4$ & 39 & $38.5 \pm 11.3$ & $12.5 \pm 7.7$ \\
$5-7$ & 15 & $53.3 \pm 11.6$ & $20.0 \pm 9.3$ \\
\hline a 12 & 70 & $35.7 \pm 11.2$ & $17.1 \pm 8.8$ \\
\hline Total & & & \\
\hline${ }^{1}$ Hemaglutinación indirecta & & &
\end{tabular}

derando una prevalencia de $3.85 \%$, tomada de un estudio realizado en búfalos del Estado de Bahía, Brasil, utilizando una técnica de aglutinación en látex (Gondim et al., 1999). Se consideró un nivel de confianza de $95 \%$ y un error esperado de $5 \%$, dando como resultado 50 animales dentro de una población de 402 (García, 2006). Sin embargo, en el estudio se llegó a muestrear a 70 animales.

La muestra se distribuyó en tres grupos etarios ( 2 a 4, 5 a 7,8 a 12 años). Se colectaron muestras de sangre solamente a animales hembras. Los sueros resultantes fueron transportados a $4{ }^{\circ} \mathrm{C}$ hasta el Centro de Investigación IVITA en Iquitos, y de allí en congelación al Laboratorio de Parasitología de la Facultad de Medicina Veterinaria, Universidad Nacional Mayor de San Marcos, en Lima.

Se empleó la técnica de hemaglutinación indirecta (HAI) para la detección de anticuerpos contra $T$. gondii mediante el kit comercial Toxotest-HAI (Wiener Lab, Argentina). Se emplearon diluciones hasta de 1/64 en los sueros. Se consideró positivos a valores $\geq 1 / 16$ (punto de corte) de acuerdo al kit. Adicionalmente y para confirmar el diagnóstico, se empleó la técnica de inmunofluorescencia indirecta (IFI) a una dilución de 1:64 (Melo de Souza et al., 2001).

\section{Resultados y Discusión}

La seroprevalencia de $T$. gondii fue de $35.7 \pm 11.2 \%$ usando la prueba de hemaglutinación indirecta (HAI) y de $17.1 \pm$ $8.8 \%$ con la técnica IFI (Cuadro 1). Esta seroprevalencia fue menor que los valores de $49.9 \%$ hallados para esta especie en Sao Paulo, Brasil con la prueba de IFI (Melo de Souza et al., 2001), aunque bastante mayores al 3.9\% de prevalencia registrada en Bahía, Brasil, con aglutinación en látex (Gondim et al., 1999).

Estas diferencias están probablemente influenciadas por factores medioambientales, presencia del hospedero definitivo (felinos domésticos y silvestres) y la técnica diagnóstica utilizada (Luzón et al., 1997). Sao Pablo posee un clima subtropical con temperaturas de 16 a $22.5^{\circ} \mathrm{C}$ y $1450 \mathrm{~mm}$ de precipitación pluvial anual. Bahía posee un clima tropical donde las temperaturas llegan hasta los $37^{\circ} \mathrm{C}$ y $1500 \mathrm{~mm}$ de precipitación y Loreto tiene un clima tropical con temperaturas que llegan hasta $32{ }^{\circ} \mathrm{C}$ y con 2000 a $3000 \mathrm{~mm}$ de precipitación. Los ooquistes, cuya ingestión es la principal forma de contagio para los hervíboros, sobreviven con más facilidad en suelos húmedos y cálidos con temperaturas alrededor de los $25^{\circ} \mathrm{C}$ (Dubey, 1994). 
La técnica de HAI posee una sensibilidad de $81.6 \%$ y una especificidad de $97.1 \%$, en tanto que la técnica IFI tiene una especificidad de $100 \%$ y sensibilidad de $75 \%$ (Ruenretai et al., 2010). No obstante, la prueba de aglutinación en látex posee una sensibilidad de $45.9 \%$ y una especificidad de 96.6\% (Dubey, 1995), pudiendo ser esta la causa de los bajos valores de seroprevalencia en los búfalos de Bahia (Gondim et al., 1999).

La prueba «Dye test» es la prueba «gold standard» para el diagnóstico de toxoplasmosis en el hombre; sin embargo, la prueba ha demostrado ser poco confiable en otras especies. Por otro lado, la inmunofluorescencia indirecta (IFA) es una prueba más segura y permite diferenciar los anticuerpos IgM e IgG. Asimismo, la prueba de aglutinación directa y la prueba de aglutinación en látex son relativamente rápidas y no requieren de complejas instalaciones de laboratorio, en tanto que la técnica de ELISA requiere un laboratorio con equipos más sofisticados, pero puede manejar gran número de muestras y no requiere contar con interpretación humana para el resultado (OIE, 2012).

Se debe reflexionar sobre la presencia del hospedero definitivo en el medio ambiente. La presencia de félidos silvestres, como el otorongo y el jaguar, es frecuente en Loreto, pudiendo actuar estos como diseminadores de la forma infectiva (el ooquiste). Se debe tener en cuenta que los félidos silvestres pueden sustituir al gato en las circunstancias epizootiológicas donde este último no interviene (Cordero del Campillo et al., 1999). Por otro lado, la presencia de gatos en la zona no está documentada; sin embargo, durante la toma de muestras se evidenció su presencia. Se sabe que un gato infectado puede eliminar ooquistes durante una a dos semanas y una sola deyección puede contener millones de ellos (Cordero del Campillo et al., 1999).

Se conoce que la prevalencia de toxoplasma se incrementa con la edad, ya que existe mayor riesgo de exposición al parásito a medida que aumenta la edad (García Vázquez et al., 1990; Acha y Szyfres, 1992; Botero y Restrepo, 1998). Los resultados del presente estudio coincide con esto, observándose que la prevalencia para los animales de 8 a 12 años fue de $53.3 \pm 11.6$ y de $20.0 \pm$ 9.3\% con las técnicas de HAI e IFI, respectivamente.

La seroprevalencia de $T$. gondii en búfalos de agua ha sido estudiada en muchos países, pero este pareciera ser el primer estudio serológico sobre este agente en esta especie en el país.

\section{Conclusiones}

La seroprevalencia para Toxoplasma gondii en búfalos de agua en el distrito Jenaro Herrera, Loreto, Perú, fue de de $35.71 \pm$ $11.2 \%$ con la técnica de diagnóstico de hemaglutinación indirecta (HAI) y de $17.1 \pm$ $8.8 \%$ con la técnica de inmunofluoresecencia (IFI).

\section{Literatura Cittada}

1. Acha P, Szyfres B. 1992. Zoonosis y enfermedades transmisibles comunes al hombre y los animales. $3^{\circ}$ ed. Washington, EEUU: OPS. 798 p.

2. Almaguer Y. 2007. El búfalo, una opción de la ganadería. [Internet], [2 agosto 2008]. Disponible en: http:// www.veterinaria.org/revistas/redvet/ n080807.html

3. Borghese A, Mazzi M. 2005. Buffalo population and strategies in the world. In: Buffalo production and research. REU Technical Series 67. Rome: FAO Regional Office for Europe. p 1-39.

4. Botero D, Restrepo M. 1998. Parasitosis humanas. $3^{\circ}$ ed. Medellín, Colombia: Corporación para Investigaciones Biológicas. $506 \mathrm{p}$.

5. Caldas P. 2005. Seroprevalencia del Toxoplasma gondii en borregas de una empresa ganadera de la sierra central- 
Junín. Tesis de Médico Veterinario. Lima: Facultad de Medicina Veterinaria, Univ Nacional Mayor de San Marcos. $69 \mathrm{p}$.

6. Cordero del Campillo M, Rojo Vásquez F, Martínez Fernández AR, Sánchez Acedo MC, Hernández Rodríguez S, Navarrete López-Cozar I, et al. 1999. Parasitología veterinaria. España: MacGraw Hill. 998 p.

7. Souza LM, Do Nascimento AA, Furuta PI, Basso LMS, Da Silveira DM, Da Costa AJ. 2001. Detecção de anticorpos contra Neospora caninum e Toxoplasma gondii em soros de bubalinos (Bubalus bubalis) no Estado de São Paulo, Brasil. Semina: Ci. Agrárias, Londrina 22: 39-48.

8. Dubey JP. 1994. Toxoplasmosis. J Am Vet Med Ass 205: 1593-1598.

9. Dubey JP. 1995. Duration of immunity to shedding of Toxoplasma gondii oocysts by cats. J Parasitol 81: 410-415.

10. García E. 2006. Diagnóstico del recurso ganadero en productores de la localidad de Jenaro Herrera, Distrito de Jenaro Herrera, Provincia de Requena, Departamento de Loreto, Río Ucayali, margen derecha. Tesis de Ingeniero Agrónomo. Iquitos: Univ Nacional de la Amazonía Peruana. $61 \mathrm{p}$.

11. García-Vásquez Z, Rosario-Cruz R, Solargo-Salgrado $\quad M . \quad 1990$. Prevalence of antibodies against Toxoplasma gondii in sheep and goats in three states of Mexico. Prev Vet Med 10: 25-29.

12. Gómez O, Chávez A, Casas E, Serrano E, Cárdenas O. 2003. Determinación de la prevalencia de la toxoplasmosis en alpacas y llamas en la estación experimental INIA-Puno. Rev Inv Vet Perú 14: 49-53.

13. Gondim LF, Barbosa HV, Ribeiro Filho CH. 1999. Serological survey of antibodies to T. gondii in goats, sheep, cattle and water buffaloes in Bahia State, Brazil. Vet Parasitol 82: 273-276.
14. Hamidinejat H, Ghorbanpour M, Nabavi L, Haji Hajikolaie MR, Razi Jalali MH. 2010. Seroprevalence of Toxoplasma gondii in water buffaloes (Bubalus bubalis) in South-West of Iran. Trop Biomed 27: 275-279.

15. Isuiza M, Pezo R, López J. 1996. Estudio sobre el búfalo de agua en Jenaro Herrera. Doc Téc N. ${ }^{\circ}$ 23. Iquitos: Instituto de Investigación de la Amazonía Peruana. $63 \mathrm{p}$.

16. Luzón M, Alonso A, Quintanilla GA. 1997. Etiología y biología. Toxoplasmosis-Neosporosis. Aula Veterinaria Ovis 52: 11-31.

17. [OIE] World Organisation for Animal Health. 2012. Manual of diagnostic tests and vaccines for terrestrial animals. [Internet]. Available in: http:// www.oie.int/manual-of-diagnostic-testsand-vaccines-for-terrestrial-animals/

18. Pastor J, Chávez A, Casas E, Serrano E. 2003. Seroprevalencia de $T$. gondii en vicuñas de Puno. Rev Inv Vet Perú 14(1): 79-82.

19. Poma E, Chávez A, Casas E, Falcón $N$, Zárate D. 2008. Seroprevalencia de anticuerpos contra Toxoplasma gondii en alpacas (Lama pacos) de una unidad de producción de la Sierra Central del Perú. Rev Inv Vet Perú 19: 43-38.

20. Rojas M, Lobato I, Montalvo C. 1989. Prevalencia de Toxoplasma gondii en camélidos sudamericanos. En: Res XII Reunión Científica Anual del APPA. Ayacucho, Perú.

21. Rojas M. 1990. Parasitismo de los rumiantes domésticos: terapia, prevención y modelos para su aprendizaje. Lima. Ed. Maijosa. 383 p.

22. Ruenruetai $U$, Ruangrat B, Yaowalark S. 2010. Is Sabin-Feldman dye test using $T$. gondii tachyzoites from animal inoculation still the best method for detecting Toxoplasma gondii antibodies? Southeast Asian J Trop Med Public Health 41: 1059-1064.

23. Saavedra GM, Ortega YR. 2004. Seroprevalence of Toxoplasma gondii 
in swine from slaughterhouses in Lima, Peru, and Georgia, U.S.A. J Parasitol 90: 902-904.

24. Saravia M, Chávez A, Casas E, Falcón N, Pinto W. 2004. Seroprevalencia de Toxoplasma gondii en llamas en una empresa pecuaria en Melgar, Puno. Rev Inv Vet Perú 15: 49-55.

25. Selvaraj J, Manohar BM, Singh S, Balachandran C.2007. Seroprevalence of Toxoplasma gondii in buffaloes. J Vet Parasitol 21: 41-42.
26. Tejada A, Balbin G. 1989. Situación actual del estudio de la Toxoplasmosis en el Perú. En: Anales del Seminario Nacional de Zoonosis y Enfermedades de Transmisión Alimentaria. Lima. Perú.

27. Thrustfield M. 1990. Epidemiología veterinaria. España: Acribia. 339 p.

28. Vidal L. 1990. Prevalencia de anticuerpos contra Toxoplasma gondii en cabras de la provincia de Lima. Tesis de Médico Veterinario. Lima. Univ Nacional Mayor de San Marcos. 41 p. 